\title{
Preliminary test: Evaluation and selection of tomato (Lycopersicon esculentum Mill.) varieties resistant to drought and powdery mildew
}

\author{
Mohunnad Massimi ${ }^{1,2 *}$ - Laszlo Radocz ${ }^{2}$ \\ ${ }^{1}$ Kerpely Kálmán Doctoral School of Crop Production and Horticultural Sciences \\ ${ }^{2}$ Institute of Plant Protection, University of Debrecen \\ *Correspondence: mohunnad.massimi@agr.unideb.hu
}

\begin{abstract}
SUMMARY
Powdery mildew (Leveillula taurica) and (Oidium neolycopersici) are two harmful fungi that invade the tomato (Lycopersicon esculentum Mill.) plant and grow in dry conditions. Under the influence of polyethylene glycol 6000 at a concentration of $12 \%$, the total seedlings fresh weight, total seedlings dry weight, seedling growth rate of one seedling, seedling length, and tissue water content percentage for three tomato varieties were assessed. Despite the superiority of the (Mobil) tomato variety in terms of numerical values, the results revealed no significant differences between varieties. As a result, (Mobil) has greater vigor under environmental drought stress of lower osmotic stress than other tomato varieties. More work is required to evaluate the research selection of varieties resistant to biotic stresses in dry areas, such as powdery mildew disease.
\end{abstract}

Keywords: drought, foliar, immunity, organic, pests, stress, tomato

\section{INTRODUCTION}

In the past decade, much research has focused on integrated pests management and organic farming protocols (Massimi and Radocz, 2020). One of these appropriate methods for integrated control is the preventive foliar spray for powdery mildew disease.

Powdery mildew (Leveillula taurica) is a serious fungal disease caused by a fungus that thrives in dry conditions. It is regarded as a significant tomato disease during the vegetative, flowering, and fruiting stages. However, contradictory evidence suggests that (Oidium neolycopersici) causes severe powdery mildew on all aerial parts of the tomato, except the fruit (Jacob et al., 2008). It remains unclear why powdery mildew disease in tomatoes (Lycopersicon esculentum Mill.) develops in drought conditions. This study assumes the existence of a relationship between sensitivity to drought and the high possibility of infection with powdery mildew disease and it was built on a very important hypothesis i.e. the tomato plant is very sensitive to drought. Corn, soybeans, beans, and peas are mildly drought-stressed, however, tomatoes are exceptionally drought-sensitive, according to reports (Nemeskeri and Helyes, 2019). Furthermore, cabbage, maize, melon, onion, pea, and pepper are moderate to highly drought-sensitive vegetables (Brouwer and Heibloem, 1986).

It is usually recommended, through research and agricultural extension, to select the genetic structures of summer crops, especially open field ones, that are resistant to drought and pests. One of the pioneering research experiments in this field is the experiments of selecting genotypes and varieties adapted to drought from the summer maize plant. For example, (Ahsan et al., 2013) recommended choosing corn cultivars based on the weight of the dry shoot mass. In a summer plant maize, hybrid vigor will be increased due to the stronger dominant effects of genes (Ali et al., 2014). Other similar experiments were conducted by (Massimi et al., 2020) to select drought-resistant maize hybrids based on biological growth indicators, especially the dry weight of the seedlings. However, the Association of Official Seed Analysts (AOSA, 1983) provided a complete description of the seedling growth rate test by evaluating seedlings' dry weight.

Investigating the subject of the research, which is the tomato crop, one of the important experiments in this field is the experience of testing tomato germplasm at four levels of water scarcity using polyethylene glycol $\left(0,20,40\right.$, and $\left.60 \mathrm{~g} \mathrm{~L}^{-1}\right)$. Due to their exceptional performance under all levels of water stress, the Hy-3 and MTG 1-4 tomato genotypes were discovered to be drought resistant compared with the other 14 tomato genotypes (Manoj and Uday, 2007). This study found that raising the level of polyethylene glycol reduced the seedling growth of tomato genotypes. A higher level means a higher simulation of dehydration and osmotic pressure similar to environmental drought stress on the plant.

Water scarcity has a significant impact on agricultural crop growth and productivity. As a result, a primary goal of plant breeding is to improve output in dry circumstances. The quality and vigor of seeds and the field performance of seedlings under drought conditions are among the main methods for selecting cultivars, like in tomatoes. In a study to investigate drought tolerance and produce beginning material for a drought tolerance breeding program, four commercial tomato cultivars (Imperial, Pakmore VF, Strain-B, and Tnshet Star), a drought-tolerant breeding line (L 03306), and their hybrid combinations were chosen (Wahb-Allah et al., 2011). All vegetative parameters dropped dramatically as deficit irrigation levels increased, according to the experiment. Under several deficit irrigation regimes, Pakmore VF and the breeding line L 03306 produced good yields (WahbAllah et al., 2011). The value of such a study can be summarized as follows: plant protection professionals will benefit from cultivar selection and plant breeding methods because they will gain a better understanding 
of the complex interaction between abiotic and biotic stress variables. Climate change is expected to increase the spread and intensity of both abiotic and biotic stressors, making it more likely for crops to be stressed in both ways.

Drought stress has an impact on various processes in the tomato crop, including physiology, growth, development, yield, and quality. Massimi (2021) discusses the most important research needs on the impacts of drought stress on the physiology and development of tomato crop plants, with a focus on the complicated link between drought stress and nutrient absorption. It is advocated that agricultural science study of abiotic and biotic stresses be expanded to improve organic crop production methods such as foliar nutrition as a function of integrated pest management.

The purpose of this research initial test was to evaluate the response of different drought-tolerant and non-drought tolerant tomato genotypes to simulated drought stress of an induced lower osmotic potential by proving the rate of seedling growth. The ultimate goal is to enable the researcher to select the best varieties for the trial of foliar spraying with salicylic acid which stimulates systematic acquired resistance (SAR) immunity for plants against pests, diseases, competitive weeds. In particular, the selection and recommendation of the name of the cultivar resistant to powdery mildew, which spreads in drought conditions.

\section{MATERIALS AND METHODS}

Two experiments were carried out in the laboratory of plant pathology of the Institute for Plant Protection at the school of horticulture doctorate of the University of Debrecen, Hungary. Two drought-tolerant (Mobil, and Korall) varieties and one non-drought tolerant (Tyking F1) tomato variety were randomly selected.

On the other hand, the water uptake percentage experiment with pure distilled water extends for only 24 hours. In completely randomized design and for each variety, 5 seeds were planted in 3 repetitions in 9 $\mathrm{mm}$ Petri dishes lined with two layers of filter paper type (AHLSTROM/Munksjo). Each plate was irrigated with $5-\mathrm{cm}^{3}$ of distilled water where the plates were left uncovered for 24-hours at room temperature of (20.8 ${ }^{\circ} \mathrm{C}$ ), and $(35 \%)$ relative humidity. The weight of the five seeds was measured before and after 24 hours, then the following equation of water uptake (\%) was applied according to Sozharajan and Natarajan (2014) formula:

WU $=[($ Weight After-Initial Weight $) /$ Initial Weight $] \times 100$

The second experiment extends for 12 days and was for irrigation with polyethylene glycol 6000 (ACROS Organic Germany) at a concentration of $12 \%$. In this experiment, each variety and treatment was replicated randomly three times in a split completely randomized design. Ten seeds were taken randomly from each tomato variety and seeded randomly in Petri dishes of 9-mm diameter on two layers of filter papers. Each plate was irrigated with $10-\mathrm{ml}\left(\right.$ or $10 \mathrm{~cm}^{3}$ ) of the polyethylene glycol solution 6000 of $12 \%$ concentration (24 ppm) once on the first day, with the plate being covered for 12-days to prevent the formation of the gel. A trade name of (Pancellent) digital sensor with three replicates was used to measure the total dissolved salts (TDS) in the used solutions.

On the twelfth day, five normal seedlings (full structures of shoot, root, and terminal bud) were taken from each treatment, where the total fresh weight was measured, then dried at $70{ }^{\circ} \mathrm{C}$ for 48 hours in a ventilated oven, and the total dry weight of the five seedlings was measured. The digital scale of (OHAUS adventurer) in the molecular biology lab was used. The seedling growth rate (SGR) concept was simulated as described in the Association of Official Seed Analysts (AOSA, 1983). The total dry weight of normal seedlings per treatment was divided by the number of seedlings included arriving at a seedling growth rate of gram per seedling. The tissue water content (TWC) for combined five seedlings was determined using Black and Pritchard's formula (2002):

TWC $=[($ Fresh Weight - Dry Weight $) /$ Fresh Weight $] \times 100$

The average laboratory temperature and humidity were recorded daily using a type (SENCOR SWS 5051) weather station where the average temperature and humidity were $\left(23.16^{\circ} \mathrm{C}\right.$, and $\left.34.71 \%\right)$.

Another five random plants for each variety were taken to measure the height with a centimeter ruler. The length was measured including the shoot and root together.

The inferential parametric results for this study were collected, confirmed, and their normal distribution is tested through an examination of normality using SPSS (version 26). Then, analysis of variance of a single factor (ANOVA-One Way) was used as described by (Carlberg, 2014). Means were separated according to the Least Significant Difference (LSD) at a probability level of 0.05. ANOVA findings, on the other hand, that do not reveal which variations between pairs of means are important. To investigate gaps between multiple groups' means, Post Hoc Test (Tukey-Kramer a Post Hoc Test in Excel) was used.

\section{RESULTS AND DISCUSSION}

In the water uptake percentage experiment evaluation, the seeds were irrigated with distilled water that does not exert any osmotic pressure on the seeds in an attempt to distinguish the varieties. There are no significant differences between the cultivars in the percentage of water uptake, although the droughtresistant cultivars were distinguished numerically (both Mobil, and Korall) compared to the non-resistant cultivar (Tyking F1). The equation for the percentage of water intake mathematically represents an equation corresponding to the percentage of increase in weight. It can therefore be concluded that (Mobil and Korall) seeds have higher primitive seed weights (Figure 1). 
Figure 1. Water uptake percentage of three tomato varieties

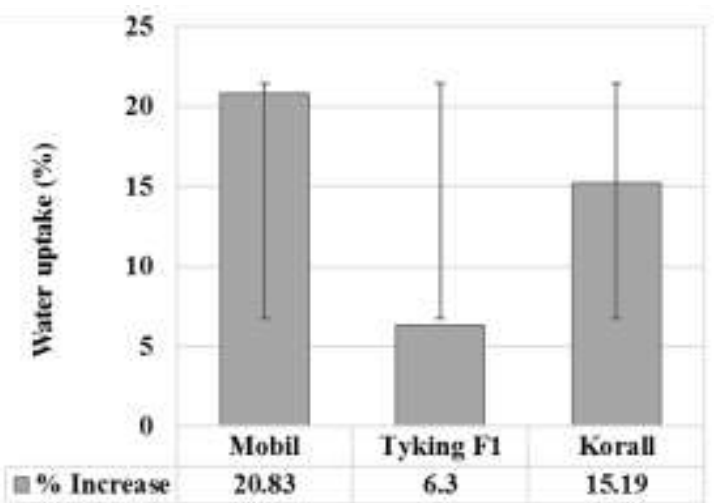

Vertical bars $( \pm)$ indicate the standard deviation of the mean $(n=3)$

The higher water absorption ratio of (Mobil, and Korall) seeds after weight gain in ratio to original seed weight by absorbing water indicates the speed of imbibitions'. Hence faster germination compared to others. The start of vital processes and the transfer of food metabolites to seed embryo with the higher relative speed than other varieties. This experiment cannot be carried out in polyethylene glycol media because opening the dish after 24 hours will lead to the crystallization of the medium and the difficulty of extracting the seeds. Even if the seeds are extracted, the readings will be inaccurate due to the viscosity of the liquid and its attachment to the seeds.

The growth rate of one seedling under the influence of simulated drought stress was favorable for the tomato variety of (Mobil). It is noticed from Table 1 that (Mobil) cultivar excelled in the weight of the five fresh seedlings and the five dry seedlings weight, although there were no significant differences with statistical significance between the three cultivars. The reason for this is due to the strength (vigor) of the variety in conditions similar to drought, where absorption and germination are faster than the rest of the varieties. The advance of the (Mobil) variety numerically over others may be due to genetic reasons. This breed can initially be selected for dry conditions. Seed weight, germination, and seed vigor increased as water imbibitions increased, as measured by seedling dry weight and seedling growth rate. This could be because (Mobil) planted seedlings have a greater respiratory rate. Wahb-Allah et al. (2011) also recorded an association between drought stress and leaf dry matter content $\%$, and stem diameter of tomato genotypes. When the amount of water delivered is reduced, it alters physiological processes and exposes plants to drought stress, resulting in limited water absorption and transmission to various plant sections. Similarly, when tested at $0,20,40$, and $60 \mathrm{~g} \mathrm{~L}^{-1}$ of polyethylene glycol, the drought-resistant $\mathrm{Hy}-3$ tomato genotype had the highest root weight $(102,44,30,22$ $\mathrm{mg}$ ), whereas the susceptible cultivar TG-5 had the lowest root weight $(20,18,14,10 \mathrm{mg}$ ) (Manoj and Uday, 2007). Further, drought-resistant tomato cultivars Hy-3, and MTG 1-4 recorded the highest shoot weights under drought level of $60 \mathrm{~g} \mathrm{~L}^{-1}$ of polyethylene glycol (Manoj and Uday, 2007).

Other investigators have found that, due to the stronger dominant effects of genes in a summer plant maize, hybrid vigor will also be increased (Ali et al., 2014). Dry seedling weight exhibited stronger genetic progress, implying that selecting tomato genotypes based on seedling weight, or growth rate could be beneficial in developing drought-tolerant tomato genotypes. Similar findings were reported on summer plant corn by (Ahsan et al., 2013; Massimi et al., 2020).

Table 1. Means of germination-imbibitions seedlings traits for tomato varieties grown in Polyethylene glycol 6000 (12\%)

\begin{tabular}{|c|c|c|c|}
\hline Genotype & $\begin{array}{c}\text { Seedling fresh weight } \\
{\left[(\mathrm{gm}) 5 \text { seedlings }^{-1}\right]}\end{array}$ & $\begin{array}{c}\text { Seedlings dry weight } \\
{\left[(\mathrm{gm}) 5 \text { seedlings }^{-1}\right]}\end{array}$ & $\begin{array}{c}\text { Seedling growth rate } \\
\left(\text { gm seedling }^{-1}\right)\end{array}$ \\
\hline Mobil & $0.075 \mathrm{~A}$ & $0.0083 \mathrm{~A}$ & $0.0017 \mathrm{~A}$ \\
\hline Tyking F1 & $0.072 \mathrm{~A}$ & $0.0077 \mathrm{~A}$ & $0.0015 \mathrm{~A}$ \\
\hline Korall & $0.066 \mathrm{~A}$ & $0.0077 \mathrm{~A}$ & $0.0015 \mathrm{~A}$ \\
\hline Significance & NS & NS & NS \\
\hline
\end{tabular}

Means in columns sharing the same letters are not significant at the 5 Percent (\%) LSD probability level. NS: Non-Significant \& S: Significant

In Figure 2, there are no significant differences between the cultivars regarding tissue water content when cultivating under simulated drought conditions and osmotic pressure. This equation is a decrease equation that explains the percentage decrease in the tissue content of water upon drying. It is noted that the fastest in losing water is the non-drought-resistant variety (Tyking F1) of $89.31 \%$ in comparison to drought-tolerant varieties of (Mobil, and Korall). When access to water is restricted, physiological processes are altered, and plants are exposed to drought stress, resulting in limited water transmission to various plant parts (Wahb-Allah et al., 2011). Plants respond to drought stress in different ways. Some plants can complete their life cycle under ideal conditions, or reduce water loss by reducing leaf size and stomatal pores. Others maintain growth even when water is scarce by retaining water content, or improve water use efficiency (WUE) of limited available water (WahbAllah et al., 2011). As a result of the quick water loss, it may be concluded that (Tyking F1) is the least drought-resistant of the species. 
Figure 2. Tissue water content (\%) for tomato varieties germinated in Polyethylene glycol solution

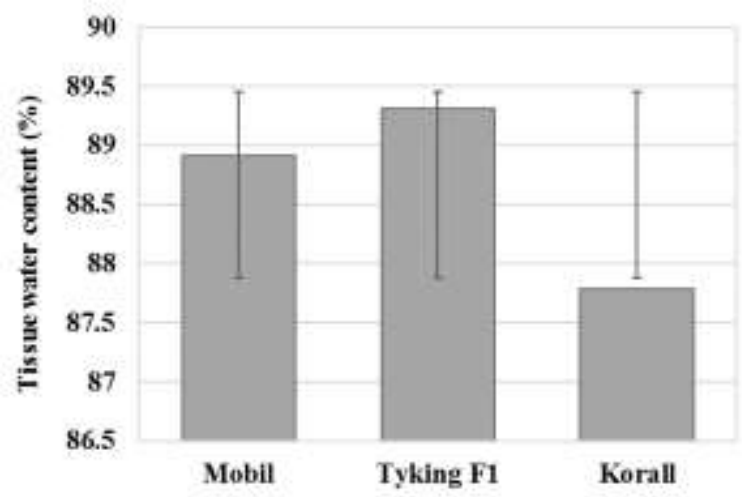

Vertical bars $( \pm)$ indicate the standard deviation of the mean $(n=3)$

Table 2 shows the average length of five seedlings for each variety. The drought-resistant cultivars (Mobil, and Korall) outperformed the non-drought-resistant cultivar (Tyking F1) in the total seedling length $(\mathrm{cm}$ seedling $\left.{ }^{-1}\right)$.

Early and fast root extension is a key indicator of drought resistance. Some plants of the non-resistant variety (Tyking F1) behaved the same as the resistant varieties at the beginning only and did not continue like the resistant varieties (Mobil, and Korall). It was observed that root length $(3.1 \mathrm{~cm})$ and shoot length $(4.3$ $\mathrm{cm})$ were the highest for the tomato resistant variety Hy-3 under the highest drought level of PEG $60 \mathrm{~g} \mathrm{~L}^{-1}$ (Manoj and Uday, 2007) compared with other varieties. A similar conclusion found drought stress significant and negative impact on the length of tomato plant genotypes (Wahb-Allah et al., 2011). This is further evidence of the phenotypic vigor as a function of the genetic structure for resistant varieties compared with others.

The results described in this study indicate the vigor of (Mobil) tomato under lower osmotic potential stress compared to other genotypes. One explanation is the (Mobil) genotype variety's ability to absorb water faster, leading to faster germination and growth than other varieties. (Mobil) variety can develop and hold more tissue water under induced drought stress of around $(-0.45 \mathrm{Mpa})$, which was previously determined at (10\% of polyethylene glycol 6000) (Jacomini et al., 1988).

Table 2. Average length of five seedlings for each cultivar at the end of a simulated drought stress experiment

\begin{tabular}{cc}
\hline Genotype & $\begin{array}{c}\text { Seedling length } \\
\text { cm seedlings }^{-1}\end{array}$ \\
\hline Mobil & $7.20 \mathrm{~A}$ \\
Tyking F1 & $6.18 \mathrm{~A}$ \\
Korall & $7.24 \mathrm{~A}$ \\
\hline Significance & $\mathrm{NS}$ \\
\hline
\end{tabular}

Means in columns sharing the same letters are not significant at the 5 Percent (\%) LSD probability level. NS: Non-Significant \& S: Significant.

More research is needed to determine the research selection of drought-tolerant cultivars (Mobil and Korall), as well as other parameters such as shoot and seedling length at the stage of two to three true leaves. Foliar spraying with a lower concentration of 50 $\mathrm{mg} \mathrm{L}^{-1}$ salicylic acid solution will provide more accurate results on genotypes that are better suited to environmental circumstances and biotic pressures such as insects, pathogens, fungal diseases, as well as competitive weeds of open field gardening.

\section{CONCLUSIONS}

When compared to other tomato varieties, the results of this study clearly show (Mobil) tomato vigor under lower osmotic potential stress. The study recommends raising the percentage of polyethylene glycol to filter the selection of cultivars more accurately. Foliar spraying with a salicylic acid solution can produce more consistent results on varieties that are best suited to powdery mildew disease.

\section{ACKNOWLEDGEMENTS}

The authors are grateful to the employees and students of the University of Debrecen's Institute of Plant Protection for their assistance and encouragement.

\section{REFERENCES}

Ahsan, M.-Farooq, A.-Khaliq, I.-Ali, Q.-Aslam, M.-Kashif, M (2013): Inheritance of Various Yield Contributing Traits in Maize (Zea mays L.) at Low Moisture Condition. Afr J Agric Res. 8: 413-420.

Ali, F.-Ahsan, M.-Saeed, N.A.-Ahmed, M.- Ali, Q.-Kanwal, N.Tehseen, M.M.-Ijaz, U.-Bibi, I.-Niazi, N.K. (2014): Establishment and Optimization of Callus-to-Plant Regeneration System Using Mature and Immature Embryos of Maize (Zea mays). Int J Agric Biol. 16: 111-117.
Association of Official Seed Analysts, (AOSA) (1983): Seed Vigor Testing Handbook, Contribution No. 32 to the handbook of seed testing.

Black, M.-Pritchard, H.W. (2002): Desiccation and Survival in Plants Drying Without Dying, New York: CABI publishing.

Brouwer, C.-Heibloem, M. (1986): Crop Water Needs, Irrigation Water Management: Irrigation Water Needs, Food and Agricultural Organization, Rome.

Carlberg, C. (2014): Statistical Analysis: Microsoft Excel 2013, Que Publishing. 
Jacob, D.-Rav David, D.-Sztjenberg, A.-Elad, Y. (2008) Conditions for Development of Powdery Mildew of Tomato Caused by Oidium neolycopersici. Phytopathology. 98: 270281

Jacomini, E.-Bertani, A.-Mapelli, S. (1988): Accumulation of Polyethylene glycol 6000 and its Effect on Water Content and Carbohydrate Level in Water-Stressed Tomato Plants. Can J Bot. 66: 970-973.

Manoj, K.-Uday, D. (2007): In vitro Screening of Tomato Genotypes for Drought Resistance Using Polyethylene Glycol. African Journal of Biotechnology. 6(6).

Massimi, M. (2021): Tomato (Lycopersicon esculentum Mill.) Anatomical, Physiological, Biochemical and Production Responses to Drought Stress-A Mini-Review Essay. International Journal of Horticultural Science. 27, 40-45.
Massimi, M.-Hasseb, M.-Legaspi, J. (2020): Growth Biometrics Response of Silage Corn and Forage Sorghum to Hybrid Vigor Under Multiple Irrigation Treatments. Int J Agric Sci.5: 14-24. Massimi, M.-Radocz, L. (2020): A Brief Literature Investigations on Foliar Plant Nutrition and its Function in the Protection of Horticultural Crops. Hung Agric Eng J. 38: 63-70.

Nemeskéri, E.-Helyes, L. (2019): Review: Physiological Responses of Selected Vegetable Crop Species to Water Stress. Agronomy. 9 (8), 447.

Sozharajan, R.-Natarajan, S. (2014): Germination and Seedling Growth of Zea mays L. Under Different Levels of Sodium Chloride Stress. Int Lett Nat Sci. 12: 5-15.

Wahb-Allah, M.-Alsadon, A.-Ibrahim, A. (2011): Drought Tolerance of Several Tomato Genotypes Under Greenhouse Conditions. World Applied Sciences Journal. 15(7), 933-940. 
